\title{
Stability Analysis of Uncertain Temperature control system with two additive delays and nonlinear perturbation
}

\author{
Venkatachalam Veeraragavan ${ }^{*}$ \\ Coimbatore Institute of Technology, Coimbatore-641014, India \\ "Corresponding Author: vikranth6488@gmail.com \\ Prabhakaran Duraisamy \\ Coimbatore Institute of Technology, Coimbatore-641014, India \\ dprabhakaran68@gmail.com \\ Thirumarimurugan Murugan \\ Coimbatore Institute of Technology, Coimbatore-641014, India \\ Thirumarimurugan@gmail.com \\ Ramakrishnan Krishnan \\ Pondicherry Engineering College, Pondicherry-605014, India \\ ramakrishnan@pec.edu
}

\begin{abstract}
In this paper, the problem of robust delay-dependent stability criterion is considered for a class of linear continuous time heat exchanger system with constant additive state-delays and bounded nonlinear perturbations using LyapunovKrasovskii (LK) functional approach. In the proposed delay-dependent stability analysis, the time-delays are considered to be time-invariant. In the proposed delay-dependent stability analysis, a candidate LK functional is considered, and take the time-derivative of the functional is bounded using the Jenson integral inequality. The proposed stability analysis finally culminates into a stability criterion in LMI framework. The effectiveness of the proposed stability criterion is illustrated using a network controlled temperature control of heat exchanger system
\end{abstract}

\section{Indexing terms/Keywords}

Constant Additive Time-Delay, Delay-dependent stability, Jenson Integral Inequality, Lyapunov-Krasovskii Functional, Nonlinear perturbations, Temperature Control system.

\section{INTRODUCTION}

Retarded time-delay differential equations with two additive state-delays provide ideal mathematical explanation for Networked Control Systems (NCSs) [1]. In real time conditions, the two time-delays in a typical NCS arise due to the transfer of state information from the plant to the controller and the succeeding transfer of controlled effort from the controller to the actuator to operate the plant $[2,3]$. Since these two time-delays, owing to the network conditions, have unalike characteristic, analysis and synthesis of this class of time-delay systems pose interesting challenges and problems to the control engineering community [3]. Delay-dependent stability analysis of temperature control of heat exchanger system, based on Lyapunov-Krasovskii (LK) functional approach, yields sufficient conditions for computing the maximum allowable bound of the time-delays within which the temperature control of heat exchanger system under consideration remains asymptotically stable in the sense of Lyapunov. These sufficient conditions, referred generally as delaydependent stability criteria, are expressed as a set of solvable LMI conditions. The conservatism of delay-dependent stability criteria depends mainly on the choice of the LK functional used in the analysis, and the techniques, many useful results have been reported in literature in recent time [2-13]. Among these results, expect [14], all the other result present stability criteria for nominal systems with additive state-delays; in [14], a robust stability criterion is derived for additive state-delayed systems with time-varying parametric uncertainties.

In spite of many useful results existing in literature, there are no results available for ascertaining delay-dependent stability of linear (heat exchanger) system with additive state-delays subjected to bounded nonlinear perturbations. These nonlinear perturbations, expressed with respect to current and delayed states, account for system uncertainties like noisy ambient conditions, slowly varying system parameters etc., refer $[14,15,20]$. The robustness of nonlinear perturbed heat exchanger system can be ascertained by delay-dependent stability analysis based on Lyapunov approach [19]. Proposing one such analysis is the objective of this paper. In the proposed analysis, with the assumption that the network delays are constant, a fewer conservative delay-dependent stability criterion is derived using LK functional approach and Jenson integral inequality [16] in LMI formulation. By making use of this integral inequality, there is a substantial reduction in number of free-weighting matrices employed in the delay-dependent stability analysis. Since the proposed robust stability criterion is expressed in LMI framework, it can be solved efficiently in temperature control of heat exchanger system.

\section{System Description and Problem Statement}

In general the state-space model of the uncertain additive state-delayed temperature control of heat exchanger (PI control) system with nonlinear perturbations is given below:

$$
\begin{aligned}
& \dot{x}(t)=A x(t)+A_{d} x\left(t-h_{1}-h_{2}\right)+f+g, \\
& x(t)=\emptyset(t), t \in\left[-\left(\bar{h}_{1}+\bar{h}_{2}\right), 0\right],
\end{aligned}
$$


where $x(t) \in \mathbb{R}^{n \times 1}$ is the state vector, $A \in \mathbb{R}^{n \times n}$ and $A_{d} \in \mathbb{R}^{n \times n}$ are represents the system matrices are associated with the current state and delayed state vectors, $\emptyset(t)$ is the vector-valued continuous-time function describing the initia condition of the system, for the temperature control system state vector, and system matrices are reduced the following:

$$
A=\left[\begin{array}{cccc}
-\frac{1}{T_{V}} & 0 & 0 & 0 \\
\frac{K_{H}}{T_{H}} & -\frac{1}{T_{H}} & 0 & 0 \\
0 & \frac{K_{F}}{T_{F}} & -\frac{1}{T_{F}} & 0 \\
0 & 0 & 1 & 0
\end{array}\right] ; \quad A_{d}=\left[\begin{array}{cccc}
0 & 0 & \frac{-K_{P} K_{V}}{T_{V}} & \frac{-K_{I} K_{V}}{T_{V}} \\
0 & 0 & 0 & 0 \\
0 & 0 & 0 & 0 \\
0 & 0 & 0 & 0
\end{array}\right]
$$

The additive state-delays $h_{1}$ and $h_{2}$ satisfy the following conditions:

$$
0 \leq h_{1} \leq \bar{h}_{1}, \quad 0 \leq h_{2} \leq \bar{h}_{2}
$$

where $\bar{h}_{1}$ and $\bar{h}_{2}$ are the upper bound of the time-delays $h_{1}$ and $h_{2}$. In (1), the terms $f=f(x(t), t)$ and $g=g\left(x\left(t-h_{1}-\right.\right.$ $h 2, t$ represents the nonlinear perturbations with respect to current state and additive delayed state; they are assumed to satisfy $f(0, t)=g(0, t)=0$ and following bounding conditions:

$$
\begin{gathered}
f^{T} f \leq \alpha^{2} x^{T}(t) F^{T} F x(t), \\
g^{T} g \leq \beta^{2} x^{T}\left(t-h_{1}-h_{2}\right) G^{T} G x\left(t-h_{1}-h_{2}\right),
\end{gathered}
$$

where $F$ and $G$ are known constant matrices of appropriate dimensions; the non-negative scalars $\alpha$ and $\beta$ quantify the magnitude of the nonlinear perturbations. The problem addressed in this paper is stated below:

To develop a robust stability criterion in LMI framework to ascertain delay-dependent stability of the system (1) subject to bounding conditions (3) and (4), and satisfying the additive time-delays (2) using Lyapunov-Krasovskii (LK) functional approach and Jenson integral inequality lemma. For deriving the robust stability criterion, following lemmas are unavoidable:

Lemma 1: For any positive symmetric constant matrix $M \in \mathbb{R}^{n \times n}$, scalar $r_{1}$ and $r_{2}$ satisfying $r_{1}<r_{2}$, a vector valued function $\omega:\left[r_{1}, r_{2}\right] \rightarrow \mathbb{R}^{n}$ such that the integrations related are well defined, then following inequality holds:

$$
\left(\int_{r_{1}}^{r_{2}} \omega(s) d s\right)^{T} M\left(\int_{r_{1}}^{r_{2}} \omega(s) d s\right) \leq r_{12} \int_{r_{1}}^{r_{2}} \omega^{T}(s) M \omega(s) d s .
$$

where $r_{12}=r_{2}-r_{1}$.

Lemma 2: For a continuous function $f(x)$ and its derivative $f^{\prime}(x)$ defined on $[a, b]$, then

$$
\int_{a}^{b} f^{\prime}(x) d x=f(b)-f(a)
$$

Lemma 3: For any positive symmetric constant matrix $Z \in \mathbb{R}^{n \times n}$, scalars $\gamma_{1}$ and $\gamma_{2}$ satisfying $\gamma_{1} \leq \gamma_{2}$, a vector valued function $x(t-\gamma):\left[\gamma_{1}, \gamma_{2}\right] \rightarrow \mathbb{R}^{n}$ such that the integration concerned as well defined, then following inequality holds:

$$
-\gamma_{12} \int_{t-\gamma_{2}}^{t-\gamma_{1}} \dot{x}^{T}(s) Z \dot{x}(s) d s \leq\left[\begin{array}{l}
x\left(t-\gamma_{1}\right) \\
x\left(t-\gamma_{2}\right)
\end{array}\right]^{T}\left[\begin{array}{cc}
-Z & Z \\
Z & -Z
\end{array}\right]\left[\begin{array}{l}
x\left(t-\gamma_{1}\right) \\
x\left(t-\gamma_{2}\right)
\end{array}\right]
$$

Proof: By Lemma 1, we can write the following expression $\left(\omega(s)=\dot{x}(s), M=Z, r_{1}=t-\gamma_{2}, r_{2}=t-\gamma_{1}\right)$ :

$$
-\gamma_{12} \int_{t-\gamma_{2}}^{t-\gamma_{1}} \dot{x}^{T}(s) Z \dot{x}(s) d s \leq\left(\int_{t-\gamma_{2}}^{t-\gamma_{1}} \dot{x}(s) d s\right)^{T}(-Z)\left(\int_{t-\gamma_{2}}^{t-\gamma_{1}} \dot{x}(s) d s\right)
$$

By Lemma 2, we can express (6) as follows $\left(f()=.x(s), a=t-\gamma_{2}, b=t-\gamma_{1}\right)$ :

$$
-\gamma_{12} \int_{t-\gamma_{2}}^{t-\gamma_{1}} \dot{x}^{T}(s) Z \dot{x}(s) d s \leq\left(x\left(t-\gamma_{1}\right)-x\left(t-\gamma_{2}\right)\right)^{T}(-Z)\left(x\left(t-\gamma_{1}\right)-x\left(t-\gamma_{2}\right)\right),
$$

which, in other words, is expressed quadratically as stated in (5) of the lemma. 


\section{Main Result}

The main result of the paper is stated in the form of a Theorem:

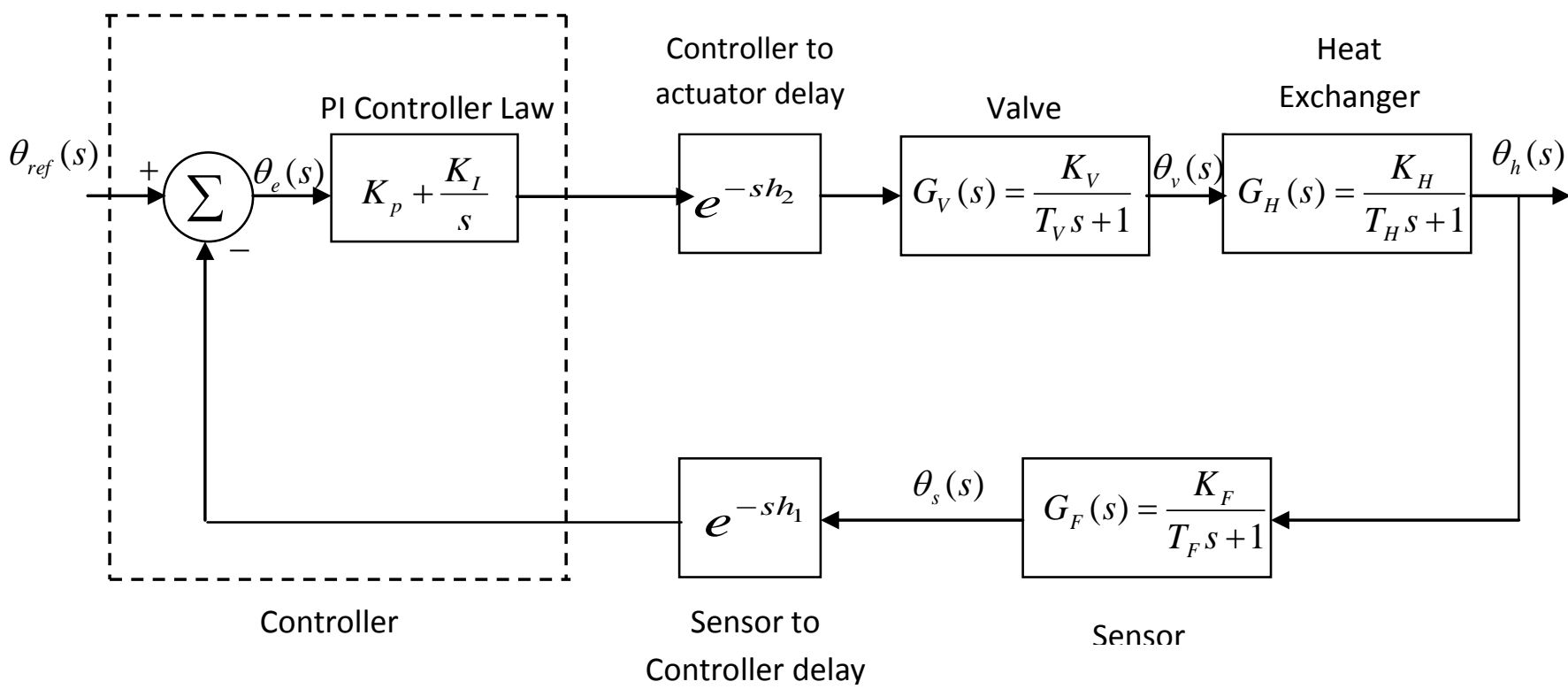

Fig. 1 Block diagram of closed loop temperature control of heat exchanger system with constant additive-delays

Theorem: The LTI system (1) is asymptotically stable in the sense of Lyapunov for a given value of $\bar{h}_{1}$ and $\bar{h}_{2}$, if there exist real symmetric positive definite matrices $P, Q_{1}, Q_{2}$, and $R$; scalars $\varepsilon_{1}>0$ and $\varepsilon_{2}>0$ such that the LMI (17).

Proof: The Lyapunov-Krasovskii (LK) functional approach are used in the delay-dependent stability analysis of a LTI system controlled over a delayed network is given by

$$
V(x(t))=V_{1}(x(t))+V_{2}(x(t))+V_{3}(x(t)),
$$

where

$$
\begin{gathered}
V_{1}(x(t))=x^{T}(t) P x(t) \\
V_{2}(x(t))=\int_{t-h_{1}}^{t} x^{T}(s) Q_{1} x(s) d s+\int_{t-h}^{t} x^{T}(s) Q_{2} x(s) d s, \\
V_{3}(x(t))=\int_{-h}^{0} \int_{t+\theta}^{t} \dot{x}^{T}(s) R \dot{x}(s) d s d \theta,
\end{gathered}
$$

where $P, Q_{1}, Q_{2}$ and $R$; are real symmetric positive definite matrices and $h=h_{1}+h_{2}$. The time derivative of the $\mathrm{LK}$ functional $V_{i}(x(t)), i=1,2,3$ is given by

$$
\begin{gathered}
\dot{V}_{1}(x(t))=\dot{x}^{T}(t) P x(t)+x^{T}(t) P \dot{x}(t), \\
\dot{V}_{1}(x(t))=\left(A x(t)+A_{d} x\left(t-h_{1}-h_{2}\right)+f(x(t), t)+g\left(x\left(t-h_{1}-h_{2}\right), t\right)\right)^{T} P x(t)+x^{T}(t) P\left(A x(t)+A_{d} x\left(t-h_{1}-h_{2}\right)+\right. \\
f x t, t+g x t-h 1-h 2, t, \\
\dot{V}_{2}(x(t))=x^{T}(t) Q_{1} x(t)-x^{T}\left(t-h_{1}\right) Q_{1} x\left(t-h_{1}\right)+x^{T}(t) Q_{2} x(t)-x^{T}(t-h) Q_{2} x(t-h), \\
\dot{V}_{3}(x(t))=h \dot{x}^{T}(t) R \dot{x}(t)-\int_{t-h}^{t} \dot{x}^{T}(s) R \dot{x}(s) d s \\
\dot{V}_{3}(x(t))=h \dot{x}^{T}(t) R \dot{x}(t)-\int_{t-h}^{t-h_{1}} \dot{x}^{T}(s) R \dot{x}(s) d s-\int_{t-h_{1}}^{t} \dot{x}^{T}(s) R \dot{x}(s) d s .
\end{gathered}
$$

Now, for any $\varepsilon_{1} \geq 0$ and $\varepsilon_{2} \geq 0$, it follows from (3) and (4) that

$$
\begin{gathered}
\varepsilon_{1}\left(\alpha^{2} x^{T}(t) F^{T} F x(t)-f^{T} f\right) \geq 0 \\
\varepsilon_{2}\left(\beta^{2} x^{T}\left(t-h_{1}-h_{2}\right) G^{T} G x\left(t-h_{1}-h_{2}\right)-g^{T} g\right) \geq 0
\end{gathered}
$$

Now, by applying Lemma 3 on (13), and by adding the positive quantities (14) and (15) to $\sum_{i=1}^{3} \dot{V}_{i}(x(t))$, we express $\dot{V}(x(t))$ as follows:

$$
\dot{V}(x(t)) \leq \xi^{T}(t) \Pi \xi(t)
$$


The augmented state vector is:

$$
\xi(t)=\left[\begin{array}{ccccc}
x^{T}(t) & x^{T}\left(t-h_{1}\right) & x^{T}\left(t-h_{1}-h_{2}\right) & f(.)^{T} & g(.)^{T}
\end{array}\right]^{T}
$$

Now, if $\Pi<0$, there exists a sufficient small scalar $\alpha>0$ such that $\dot{V}(x(t)) \leq-\alpha\|x(t)\|^{2}$, which, in turn, implies that the additive state-delayed system (1) is asymptotically stable in the sense of Lyapunov. By taking Schur complement [17] on $\Pi<0$, we deduce the delay-dependent stability criterion (LMI (17)) stated in the Theorem 1.

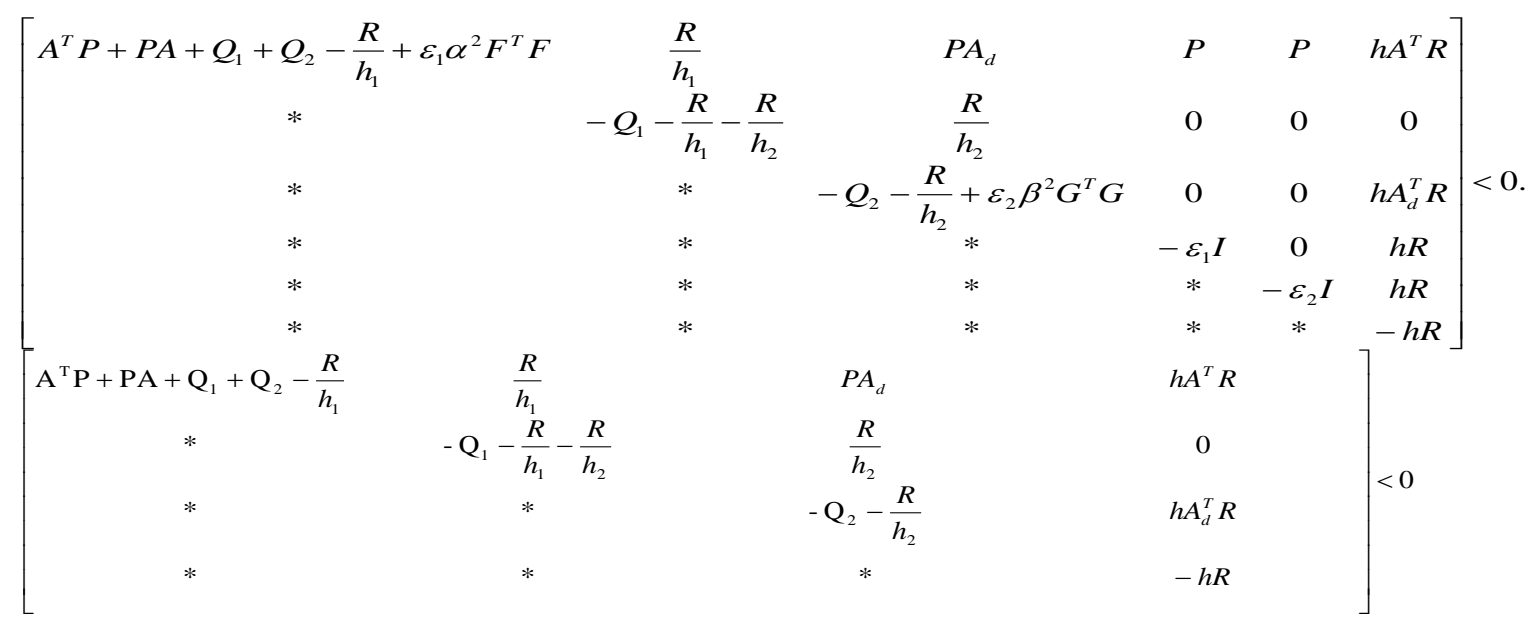

*-Represents the symmetric matrices

Remark: For nominal system with $f()=.g()=$.0 , the delay-dependent stability criterion is presented in following corollary:

Corollary 1: The LTI system (1) with $f()=.g()=$.0 is asymptotically stable in the sense of Lyapunov for a given value of $\bar{h}_{1}$, and $\bar{h}_{2}$, if there exists real symmetric positive definite matrices $P, Q_{1}, Q_{2}$ and $R$ such that the LMI (18) stated.

\section{Temperature Control System}

For the temperature control of heat exchanger system, linear or linearized models are commonly used to analyze the system dynamics and to design a controller. Fig.1 shows the block diagram of a temperature control of heat exchanger system with including network-induced time-delays. Now that each component of the system namely heat exchanger, sensor, valve, controller is modelled by a first-order transfer function [18]. They repeated here for convince:

$$
\mathrm{G}_{\mathrm{V}}(\mathrm{s})=\frac{\mathrm{K}_{\mathrm{V}}}{\mathrm{T}_{\mathrm{V}} \mathrm{s}+1} ; \mathrm{G}_{\mathrm{H}}(\mathrm{s})=\frac{\mathrm{K}_{\mathrm{H}}}{\mathrm{T}_{\mathrm{H}} \mathrm{s}+1} ; \mathrm{G}_{\mathrm{F}}(\mathrm{s})=\frac{\mathrm{K}_{\mathrm{F}}}{\mathrm{T}_{\mathrm{F}} \mathrm{s}+1} ;
$$

where $\mathrm{K}_{\mathrm{V}}, \mathrm{K}_{\mathrm{H}}$ and $\mathrm{K}_{\mathrm{F}}$ are the gains of valve, heat exchanger and sensor respectively, and $\mathrm{T}_{\mathrm{V}}, \mathrm{T}_{\mathrm{H}}$ and $\mathrm{T}_{\mathrm{F}}$ are the corresponding time constants.

In the Fig.1 Portrays sensor to controller delay and portrays controller to actuator delay. The transfer function of the controller is given below.

$$
\mathrm{G}_{\mathrm{C}}(\mathrm{s})=\mathrm{K}_{\mathrm{P}}+\frac{\mathrm{K}_{\mathrm{I}}}{\mathrm{s}}
$$

where $\mathrm{K}_{\mathrm{P}}$ and $\mathrm{K}_{\mathrm{I}}$ are the proportional and integral controller gains respectively; the proportional term control the rate of temperature rise after initial transients. The integral controller gain adds a pole at origin and increases the system type by one and hence reduces the steady-state error. The coordinated effort of the PI controller gains will structure the response of the temperature control of heat exchanger with reduced overshoot and faster settling time.

\section{Case Study}

In this section, the potency of the proposed stability criterion for temperature control of heat exchanger system with constant additive time delays is illustrated.

Table.1 Parameter values of Temperature Control system

\begin{tabular}{|l|c|c|}
\hline System & Gain & Time-constant \\
\hline Heat exchanger & $K_{H}=34$ & $T_{H}=30$ \\
\hline Valve & $K_{V}=1.25$ & $T_{V}=3$ \\
\hline Sensor & $K_{F}=0.08$ & $T_{F}=2$ \\
\hline
\end{tabular}


In this section, the maximum allowable delay margin for constant are validated additive time-delays $\bar{h}_{1}$, and $\bar{h}_{2}$ for stability for a pick range of PI controller gains is computed. The gains and time constants of the temperature control of heat exchanger used in the analysis are as follows [18]. For the aforesaid system parameters, with delay free condition, the controller capability curve can be easily obtained; it is illustrated in Fig. 2.

From the Fig. 2, it is clear that for all values of $K_{P}$ and $K_{I}$ lying below the controller capability curve, the closed-loop system is asymptotically stable. From the curve we choose $K_{P}=0.5$ and $K_{I}=0.02 \mathrm{~s}^{-1}$ for computation of delay margin. For these controller parameters, the closed loop system converges asymptotically to equilibrium point as illustrated in Fig. 3 for a unit step perturbation in heat exchanger output variable (from its equilibrium value).

When the network delay $\hbar$ is made zero, the system equation (3) becomes

$$
\dot{x}(t)=\left(A+A_{d}\right) x(t)
$$

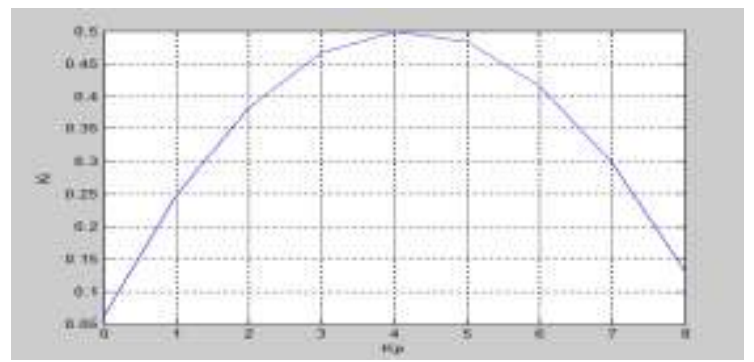

Fig. 2 The Maximum value of $K_{I}$ for different values of $K_{P}$

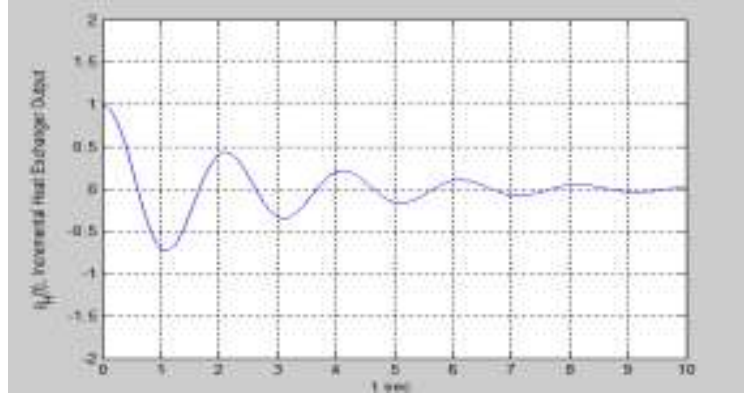

Fig. 3 Evolution of $\Delta \theta_{H}(t)$ less than zero delay condition.

Now, it is observed that the eigenvalues of the system state matrix and input matrix $\left(A+A_{d}\right)$ depend on the controller parameters $K_{P}$ and $K_{I}$. Table II given the maximum values of $K_{I} s^{-1}$ for a fixed value of $K_{P}$ for which the temperature control of heat exchanger system is on the verge of instability i.e. having one complex-conjugate pair of eigenvalues on the $j \omega$ axis. It is observed from the Fig .3 that there is a tendency for the curve to decrease gradually with increase of $K_{I}$.

In this case study corresponding to temperature control of heat exchanger system with constant additive time-delays, the exogenous load disturbance effect of temperature control of heat exchanger system is assume to satisfy the normbounded condition is given in (3) and (4); the value of two matrices $\mathrm{G}$ and $\mathrm{F}$ are taken as $0.1 I_{n}$ where $\mathrm{n}$ is the size of the system state vector $x(t)$, using Jenson integral inequality lemma stated for theorem1, the maximum value of the delay bound $h_{1}$ and $h_{2}$ is calculated for temperature control system for various values of $\alpha$ and $\beta$, as shown in Tables III and IV (refer Fig. 4 Stability margin for Temperature control of heat exchanger system). In the tables, it is clearly shows that as the values of $\alpha$ and $\beta$ increases, the load disturbance effects for the temperature control system become more pronounced, and under such load disturbed condition, the maximum value of network delay that the PI controlled temperature control of heat exchanger system withstand without losing stability decreases.

These results clearly bring out the effect of load disturbance on the delay-dependent stability of the temperature control system. Hence, delay-dependent stability analysis of temperature control of heat exchanger system with load perturbation being modelled as bounded non-linear load disturbance with respect to current and delayed state vectors has not been reported so far literature; the results presented in this paper portray a more realistic system operating condition. The nominal system condition (i.e. when $\alpha=\beta=0$ ) with two additive constant time-delays, the presented results (for ascertaining internal stability) are less conservative, and this is attributed to the higher bounding of the LyapunovKrasovskii (LK) functional in the stability analysis using the Jenson integral inequality as shows in Table $\mathrm{V}$ (for various values of $K_{P}$ and $K_{I}$ ). For choosing the controller parameter $K_{P}=0.5$ and $K_{I}=0.02 \mathrm{~s}^{-1}$, in the presence of network induced delays, according to the delay-dependent stability criterion presented in Theorem 1, the temperature control of heat exchanger system is stable upto $h_{1}=1$ second $h_{2}=18.3357$ seconds, and if network induced delays is increases far beyond this value, the system becomes unstable. 
Table .2 Maximum Integral Controller Gain for A Given $\boldsymbol{K}_{\boldsymbol{P}}$

\begin{tabular}{|c|c|c|c|}
\hline $\begin{array}{c}\text { SI.No } \\
:\end{array}$ & $\boldsymbol{K}_{\boldsymbol{P}}$ & $\boldsymbol{K}_{\boldsymbol{I}}\left(\boldsymbol{S}^{-1}\right.$ & Eigen values of $\left(\boldsymbol{A}+\boldsymbol{A}_{\boldsymbol{d}}\right)$ \\
\hline 1 & 0 & 0.062 & $\begin{array}{c}-0.4329 \pm 0.009 j ;-0.0004 ;- \\
0.0790\end{array}$ \\
\hline 2 & 1 & 0.248 & $\begin{array}{c}-0.0000 \pm 0.167 j ;-0.5801 ;- \\
0.2864\end{array}$ \\
\hline 4 & 2 & 0.382 & $\begin{array}{c}-0.0001 \pm 0.223 j ;-0.6415 ;- \\
0.2250\end{array}$ \\
\hline 5 & 3 & 0.466 & $\begin{array}{c}-0.0000 \pm 0.267 j ;-0.6885 ;- \\
0.1781\end{array}$ \\
\hline 6 & 4 & 0.499 & $\begin{array}{c}-0.0000 \pm 0.305 j ;-0.7282 ;- \\
0.1385\end{array}$ \\
\hline 7 & 5 & 0.482 & $\begin{array}{c}-0.0000 \pm 0.339 j ;-0.7631 ;- \\
0.1036\end{array}$ \\
\hline 6 & 6 & 0.415 & $\begin{array}{c}-0.0001 \pm 0.370 j ;-0.7946 ;- \\
0.0719\end{array}$ \\
\hline 8 & 7 & 0.298 & $\begin{array}{c}-0.0000 \pm 0.398 j ;-0.8236 ;- \\
0.0430\end{array}$ \\
\hline 9 & 8 & 0.130 & $\begin{array}{c}-0.0000 \pm 0.425 j ;-0.8506 ;- \\
0.0160\end{array}$ \\
\hline & & & \\
\hline
\end{tabular}

Table. 3 Maximum Allowable Delay Bound $\bar{h}_{2}$ for a given $\bar{h}_{1}$.

\begin{tabular}{|c|c|c|c|c|c|c|}
\hline Method & $\boldsymbol{\alpha}$ & $\boldsymbol{\beta}$ & $\overline{\boldsymbol{h}}_{\mathbf{1}}=\boldsymbol{0 . 1}$ & $\overline{\boldsymbol{h}}_{\mathbf{1}}=\mathbf{1}$ & $\begin{array}{c}\overline{\boldsymbol{h}}_{\mathbf{1}} \\
=\mathbf{5 . 0}\end{array}$ & $\begin{array}{c}\overline{\boldsymbol{h}}_{\mathbf{1}} \\
=\mathbf{1 0}\end{array}$ \\
\hline \multirow{3}{*}{$\begin{array}{c}\text { Theorem } \\
\mathbf{1}\end{array}$} & 0 & 0 & 19.2352 & 18.3357 & 14.3363 & 9.3366 \\
\cline { 2 - 7 } & 0 & 0.005 & 10.6649 & 9.7651 & 5.7652 & 0.7652 \\
\cline { 2 - 7 } & 0.005 & 0.005 & $\#$ & $\#$ & $\#$ & $\#$ \\
\hline
\end{tabular}

Table. 4 Maximum Allowable Delay Bound $\bar{h}_{1}$ for a given $\bar{h}_{2}$.

\begin{tabular}{|c|c|c|c|c|c|c|}
\hline Method & $\boldsymbol{\alpha}$ & $\boldsymbol{\beta}$ & $\begin{array}{c}\overline{\boldsymbol{h}}_{\boldsymbol{2}} \\
=\boldsymbol{0} . \mathbf{1}\end{array}$ & $\overline{\boldsymbol{h}}_{\boldsymbol{2}}=\mathbf{1}$ & $\overline{\boldsymbol{h}}_{\boldsymbol{2}}=\mathbf{5 . 0}$ & $\boldsymbol{h}_{\boldsymbol{2}}=\mathbf{1 0}$ \\
\hline \multirow{3}{*}{$\begin{array}{c}\text { Theorem } \\
\mathbf{1}\end{array}$} & 0 & 0 & 19.2358 & 18.3357 & 14.3363 & 9.3363 \\
\cline { 2 - 7 } & 0 & 0.005 & 10.6652 & 9.7653 & 5.7651 & 0.7651 \\
\cline { 2 - 7 } & 0.005 & 0.005 & $\#$ & $\#$ & $\#$ & $\#$ \\
\hline
\end{tabular}

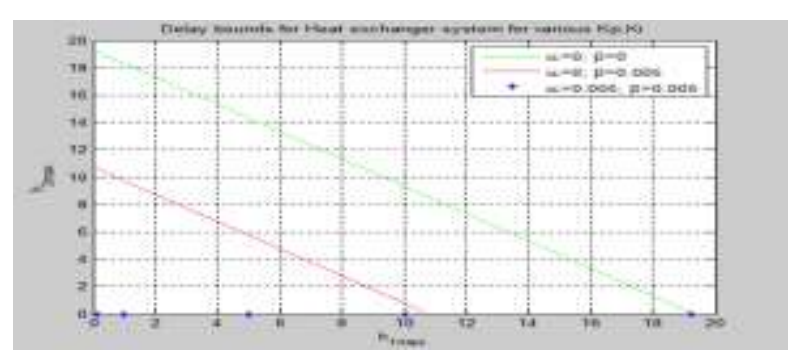

Fig. 4 Stability margin for Temperature control of heat exchanger system 
Table 5. Maximum Delay Bound for $h_{2}$ given $h_{1}$ with various controller gains

\begin{tabular}{|c|c|c|c|c|c|}
\hline $\boldsymbol{K}_{\boldsymbol{P}}$ & $\boldsymbol{K}_{\boldsymbol{I}}$ & $\boldsymbol{h}_{\mathbf{1}}=\mathbf{1}$ & $\begin{array}{c}\boldsymbol{h}_{\mathbf{1}} \\
=\mathbf{5}\end{array}$ & $\boldsymbol{h}_{\mathbf{1}}=\boldsymbol{8}$ & $\begin{array}{l}\boldsymbol{h}_{\mathbf{1}} \\
=\mathbf{1 0}\end{array}$ \\
\hline $\mathbf{0 . 2 0}$ & 0.01 & 38.29 & 34.29 & 31.29 & 29.29 \\
\hline $\mathbf{0 . 2 0}$ & 0.02 & 17.49 & 13.49 & 10.49 & 8.49 \\
\hline $\mathbf{0 . 2 0}$ & 0.03 & 10.10 & 6.10 & 3.10 & 1.10 \\
\hline $\mathbf{0 . 5 0}$ & 0.01 & 26.71 & 22.71 & 19.71 & 17.71 \\
\hline $\mathbf{0 . 5 0}$ & 0.02 & 18.33 & 14.33 & 11.33 & 9.33 \\
\hline $\mathbf{0 . 5 0}$ & 0.03 & 13.08 & 9.08 & 6.08 & 4.08 \\
\hline $\mathbf{0 . 7 5}$ & 0.01 & 16.24 & 12.24 & 9.24 & 7.24 \\
\hline $\mathbf{0 . 7 5}$ & 0.02 & 13.75 & 9.75 & 6.75 & 4.75 \\
\hline $\mathbf{0 . 7 5}$ & 0.03 & 11.40 & 7.40 & 4.40 & 2.40 \\
\hline $\mathbf{1 . 0}$ & 0.01 & 10.88 & 6.88 & 3.88 & 1.88 \\
\hline $\mathbf{1 . 0}$ & 0.02 & 9.90 & 5.90 & 2.90 & 0.90 \\
\hline $\mathbf{1 . 0}$ & 0.03 & 8.87 & 4.87 & 1.87 & $\#$ \\
\hline
\end{tabular}

\section{Conclusion}

In this paper, a robust stability criterion is proposed for a class of linear continuous time system with constant additive state-delays and bounded nonlinear perturbations using Lyapunov-Krasovskii functional approach the Jenson integra inequality, and it is expressed in Linear Matrix Inequalities (LMI) framework. The effectiveness of the proposed is illustrated in temperature control of heat exchanger system. The possibility of extending the proposed analysis procedure for an equivalent discrete-time system can be explored as a future work.

\section{Acknowledgement}

One of the authors (Dr. D. Prabhakaran) is grateful to All India Council for Technical Education (AICTE), New Delhi, India for financial support (File No. 20/AICTE/RFD/RPS (Policy-II) 23/2013-16). The authors would like to express their sincere thanks to Dr. S. R. K. Prasad (Correspondent, CIT), Dr. R. Prabhakar (Secretary, CIT), Dr. V. Selladurai (Principal, $\mathrm{CIT}$ ), for their useful discussions and encouragement during the course of work. Also we like to acknowledgement Dr. V. Manikandan (Professor, CIT) of valuable help in studying.

\section{References}

[1]. K. Ramakrishnan, G. Ray, "Stability criteria with less LMI variable for linear system with additive time-delays," Journal of Applied Mathematics and computing, vol.36, pp.263-274, 2011.

[2]. J. Lam, H. Gao, C, "Wang. Stability analysis for continuous systems with two additive time-varying delay components," system and control Letters, vol. 56, no.1, pp.16-24, 2007.

[3]. H. Gao, T. Chng, J. Lam, "A new delay system approach to network based control," Automatica, vol.44, no. 1, pp.3952, 2008.

[4]. H. Wu, X. Liao, W. Feng, S. Guo, W. Zhang, "Robust stability analysis of uncertain systems with two additive timevarying delay components", Applied Mathematical Modelling, vol. 33, no. 12, pp.4545-4353, 2009.

[5]. K. Ramakrishnan, G. Ray, "Delay-dependent stability analysis of linear system with additive time-varying delays", $5^{\text {th }}$ Annual IEEE conference on Automation Science and Engineering, Bangalore, pp. 122-126, 2009.

[6]. R. Dev, G. Ray, S. Ghosh, A. Rakshit, "Stability analysis continuous systems with additive time-carrying delays: A less conservative result," Applied Mathematics and computation, vol.215, no.10, pp.3740-3745, 2010.

[7]. H. Shao, Q.L. Han, "On Stabilization for systems with two additive time-varying input delays arising from networked control system," Journal of the Franklin Institute, vol. 349, no.6, pp. 2033-2046, 2012.

[8]. H. Shao, X. Zhu, Z. Zhang, "Delay-dependent $H_{\infty}$ control for systems with two additive time-varying delays," Journal of control Engineering and Technology, vol. 3, no. 2, pp. 90-97, 2013.

[9]. T. Li, J. Tian, "Convex polyhedron method to stability of continuous systems with two additive time-varying delays components," Journal of Applied Mathematics, Article ID, 689820, 2012.

[10]. J.W. Ko, W.I. Lee, P.G. Park, "Delayed system approach the stability of networked control systems," International multi conference of Engineering and computer scientists IMECS 2011, vol. 2.

[11]. J.M. Jiao, "A stability criterion for singular systems with two additive time-varying delay components," Internationa Journal of Automation and Computing, vol.10, no. 1, pp.39-45, 2013.

[12]. N. Chaibi, E.H. Tisser, A. Hmamed, "Delay-dependent robust stability of singular systems with additive time-varying delays," International Journal of Automation and Computing, vol.10, no.1, pp. 65-90, 2013. 
[13]. B. B. Hamed, M. Chaabane, W. Kacem, "Absolute stability of nonlinear systems with two additive time-varying delay components," vol. 8, no. 4, pp. 391-402, 2011.

[14]. W. Zhang, X.S. Cai, Z.Z. Han, "Robust stability criteria for systems with interval time-varying delay and nonlinear perturbations," Journal of Computational and Applied Mathematics, vol.234, no. 1, pp. 174-180, 2010.

[15]. K. W Yu, C. H Lien, "Stability criteria for uncertain neutral systems with interval time-varying delays," Chaos solutions and Fractals, vol. 38, No. 3, pp. 640-667, 2008.

[16]. X. L. Zhu, G.H. Yang, "Jenson integral inequality approach to stability analysis of continuous-time systems with timevarying delay," IET control Theory and Applications, vol. 2, no. 6, pp. 524-534, 2008.

[17]. S. Boyd, L. El Ghaoui, E. Feron V. Balakrishnan, "Linear Matrix Inequalities in system and control Theory," SIAM Studies in Applied Mathematics SIAM, Philedelphia U.S, 1994.

[18]. Chhaya Sharma, Sanjeev Gupta, Vipin Kumar, "Modeling and Simulation of Heat Exchanger Used in Sode Recovery", Proceedings of the World Congress on Engineering, Vol II, WCE, 2011.

[19]. K. Ramakrishnan, G. Ray, "Stability Criteria for Nonlinearly Perturbed Load Frequency Systems with Time-Delay," IEEE journal of Emerging and selected topics in Circuits and Systems, vol. 5, no. 3, pp. 383-392, 2015.

[20]. K. Ramakrishnan, G. Ray, "Stability criterion for networked control systems with additive time-varying state-delays and bounded nonlinearity," International Journal of Systems, Control and Communications, vol. 7, No. 1, pp. 68-82, 2016.

\section{Author' biography}

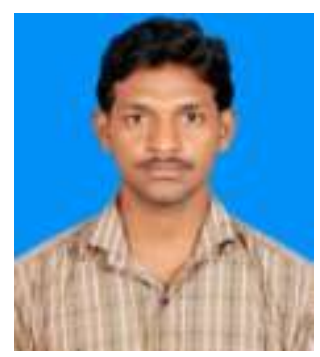

V. Venkatachalam completed B. Tech degree in Electrical and Electronics Engineering from Pondicherry University, Pondicherry, India, 2012. He completed M.Tech degree in Electrical Drives and Control from Pondicherry Engineering College, Pondicherry, India, 2015. He is currently fulltime research scholar in process dynamics and control, Coimbatore Institute of Technology, Coimbatore, India. His research interests include modelling of dynamical system with time-delays, convex optimization technique, robust control applied to time-delay systems, LMI optimization. His research was fully funded by the Technical Education Quality Improvement Programme (TEQIP) of National Project Implementation Unit (NPIU), Government of India. His previous employment was with Engineering Trainee at Mailam India Ltd., Puducherry, India, 2012-2013. Email: vikranth6488@gmail.com

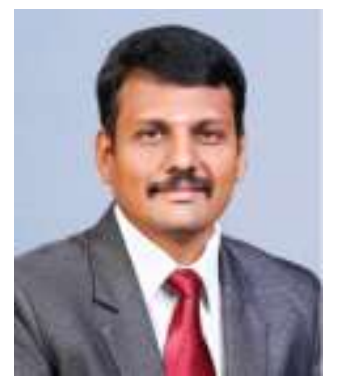

D. Prabhakaran did his Bachelor's degree in Chemical Engineering at Coimbatore Institute of Technology, April 1990. He completed Master's in Chemical Engineering at Coimbatore Institute of Technology, April 2001, Master's in Business Administration at MKU, 2002. He completed the Ph.D degree from Anna University of Technology, Coimbatore, 2011. He is working in the Department of Chemical Engineering, Coimbatore Institute of Technology, Coimbatore, India, from 1993 onwards, where he is currently an Associate Professor. His research interests include Process Dynamics and Control, Process Economics and Industrial Management, Fluidization Engineering, Environmental Engineering, Process Utilities. He has published more than 35 papers both National and International journals. He has completed two AICTE Rps project successfully. Email:dprabhakaran68@gmail.com

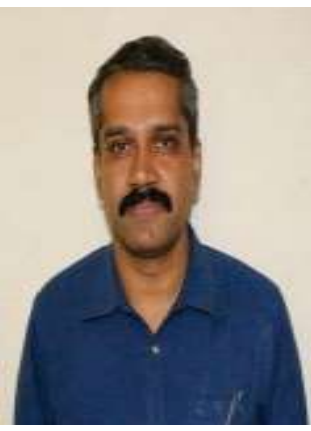

K. Ramakrishnan completed the B.E. degree in electrical and electronics engineering from Government College of Technology, Coimbatore, Tamil Nadu, India, in June 1993. He then completed the M.E. degree in control systems engineering from PSG College of Technology, Coimbatore, Tamil Nadu, India, in February 1995, through GATE scholarship. He completed the Ph.D. degree from Indian Institute of Technology, Kharagpur, West Bengal, India, in February 2014. From July 2008 to January 2012, he was a full-time research scholar with the Department of Electrical Engineering, Indian Institute of Technology, Kharagpur, West Bengal, India. His research was fully funded by the Quality Improvement Programme (QIP) of All India Council of Technical Education (AICTE), Government of India. From 2001 onwards, he is with the Department of Electrical and Electronics Engineering, Pondicherry Engineering College, Pondicherry, an autonomous institution under Government of India, where he is currently an Associate Professor. His previous employment was with Fluid Control Research Institute (FCRI) under Ministry of Defence and Heavy Industries, Government of India (1995), and Tamil Nadu Electricity Board (TNEB) as Power System Protection (Grid Relay Test) Engineer (1995-2001). His research interests include convex optimization techniques, robust control analysis/synthesis applied to time-delay systems, optimal control and LMI optimization. Email:ramakrishnan@pec.edu

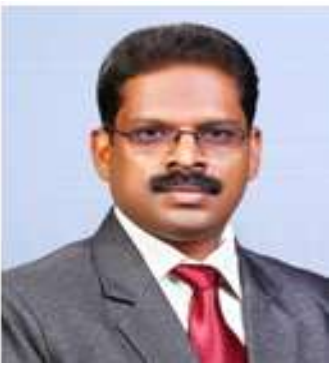

M. Thirumarimurugan obtained both his Bachelors and Masters Degree in Chemical Engineering from Bharathiar University in the years 1995 and 1997 respectively. After his B.Tech, he served as Lecturer in Erode Institute of Chemical Technology (EICT) in 1995. He is currently working as Professor in Chemical Engineering, Coimbatore Institute of Technology, Coimbatore, India. His main area of research is in Modeling, Simulation and Performance Analysis of Heat Exchangers. Recently, he has won the Best Paper Award in Energy and Environment in National Conference (NCRES2011), Anna University of Technology, Tiruchirappalli, India. He is a Life member in Indian Institute of Chemical Engineers (IIChE), Member in Indian society for Technical Education (ISTE). His research interests include modelling, simulation analysis of heat exchanger, heat transfer. Email:thirumarimurugan@gmail.com 